\title{
From the Pacific Basin
}

Peter Brooks

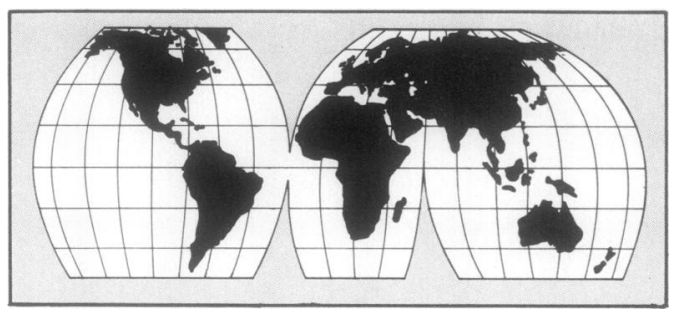

I write this dispatch by candlelight as Sydney is recovering from a violent wind and hailstorm, in which many homes were damaged by falling trees and water. We have felt relatively immune from natural disasters in this country, but over the last 12 months the power of natural forces has been brought home to us with the Newcastle earthquake, vast areas of Queensland and New South Wales flooded by torrential rain and, now, this violent storm. Being without power for five days reminds one how dependent we are on electricity and how spoilt in comparison with many of the countries in our region. In this dispatch I will concentrate on some of the countries not covered in my last article and talk particularly about the way in which the Asia/Pacific League Against Rheumatism (APLAR) is attempting to deal with the problem of rheumatic diseases on a regional basis.

It is obvious that community based research programmes and epidemiology are being adopted by a number of countries in the area. ${ }^{1}$ In the Phillipines the epidemiology of rheumatic diseases with studies of mortality and morbidity factors is being developed. There seems to be an increased interest among postgraduate doctors in the field of rheumatology, and this should make the Phillipines more able to tackle its rheumatological problems in the future. Rheumatologists in the Phillipines, as in many countries, have difficulty in providing ancillary gadgets or devices for those with disabilities because of unavailability or expense, and local materials are being developed to minimise cost.

The Hong Kong Society of Rheumatology, which was formed in 1987, has less than 30 members but holds regular postgraduate meetings with good attendances. Unfortunately, rheumatology is not recognised as a specialty in its own right as subspecialty training is limited. Rheumatologists are, however, very active within the departments of medicine at the two universities (University of Hong Kong and the Chinese University of Hong Kong) and have established major research projects into the immunogenetics of systemic lupus erythematosus and rheumatoid arthritis in Chinese patients.

The Singapore Society of Allergy, Immunology, and Rheumatology has been very active and recently hosted the successful second international conference on systemic lupus erythematosus. Five hundred and fifty delegates from over 24 countries participated in a highly successful educational meeting. The discipline has been strengthened by the return of a number of rheumatology fellows from London and Los Angeles, and the Ministry of Health in Singapore has designated the disciplines of clinical immunology and rheumatology for further development over the next few years.

The Japanese Rheumatism Association continues to be very active with over 500 papers being presented at its 34th annual scientific meeting in 1990. The Japanese Rheumatism Association funded 11 research projects during 1990 and two major prizes for rheumatology research have been established by pharmaceutical companies: CibaGeigy, Japan and Hokuriku Seiyaku. These were awarded respectively to Professor T Hirano for work on interleukin 6 in the pathogenesis of rheumatoid arthritis and Professor $T$ Ochi for work on bone marrow cells in the pathogenesis of severe rheumatoid arthritis. The Rheumatoid Arthritis Research Group has been organised by the Welfare Ministry of Japan comprising six research teams studying epidemiology, aetiology, pathophysiology, medical treatments, surgical treatments, and quality of life of patients. These projects will be funded for the next three years. Together with a number of other countries in the region, the Japanese Rheumatic Patients Corporation has been very active and ran an international symposium entitled 'The present state of rheumatic patients in foreign countries' in May 1990. A major feature of Japanese rheumatology during the year was the first examination for specialists in clinical rheumatology, which was passed by 477 rheumatologists, who obtained the title 'authorised rheumatologist'.

In November 1990 the Penang Medical Practitioners Society, in conjunction with the Malaysian Society of Rheumatology, ran an excellent teaching course on rheumatology with assistance from the United Kingdom, Canada, Australia, and other countries of the region. This was extremely successful and will hopefully be the forerunner of a number of other postgraduate courses aimed at teaching general practitioners about rheumatic diseases.

The Korean Rheumatism Association, which was founded in 1979, was the host to the first APLAR symposium on therapy of the rheumatic diseases held in November 1990. It covered the standard treatments for the rheumatic diseases, both medical and surgical, and held a number of sessions on alternative treatments, including local remedies, which might well provide therapeutic potential in the future.

APLAR has been keen to support meetings on the treatment of rheumatic diseases because they are a logical extension of the community epidemiology programmes already established throughout the area. As John Darmawan, secretary-general of APLAR, pointed out recently, ${ }^{2}$ two thirds of the world's population live in the developing countries of the Asia/Pacific area and there are probably half a billion patients with rheumatic complaints requiring attention. Many treatments are obtained over the counter and it is extremely
Department of Royal North Shore Hospital, St Leonards, NSW 2065, Australia P Brooks 
important to provide the community, as well as local doctors, with as much information as possible about drugs and other treatments. To this end the COPCORD project is developing a series of simple treatment manuals for primary health care workers and expanding its patient education in a variety of ways, including television, radio, and print. ${ }^{1}$

APLAR is supporting Dr Grigor to visit some of the small Pacific islands, such as Tonga, Rarotonga, and Western Samoa, to give a series of lectures and to review the prevalence of rheumatic diseases in those communities. Professor Torralba has recently visited Vietnam to lecture on rheumatic conditions and it is hoped that this will act as a further stimulus to rheumatology in that country.

Training fellowships in epidemiology have been established in Newcastle, Australia, and at McMaster University in Canada and APLAR is hoping to provide training for rheumatologists from the area in this discipline. Obviously, the three areas of education-undergraduate, postgraduate, and patient education-still require an enormous amount of effort but they are improving, and APLAR is giving considerable time to developing these areas over the next three years. The APLAR bulletin, which is edited by Ray Robinson and Ken Muirden, continues to be an excellent source of information on activities within the region.

In Australia we are currently having a major review of the health care system brought about, to a large extent, by our diminishing financial resources. Although it is probably appropriate to review directions of health care delivery and to reorient them towards the community, those of us within the teaching hospitals have some fear that the teaching institutions will suffer significantly from any redistribution of funds. This is likely to have major adverse effects on research activities and critical evaluation of new technologies.

The biennial scientific meeting of the New Zealand Rheumatism Association and the Australian Rheumatism Association (now the Australian Rheumatology Association and the only ARA) was held in September 1990 amidst the snowfields of New Zealand's South Island. The three major symposiums on bone metabolism, systemic lupus erythematosus, and outcomes in rheumatic diseases kept people off the ski slopes with excellent contributions from visitors John Kanis, Bevra Hahn, and Matthew Liang. The rheumatology health professionals of New Zealand and Australia also met concurrently with Patricia Le Gallez describing the role of the nurse/practitioner in rheumatology as established by the Rheumatism Research Unit in Harrogate. The free papers covering areas from basic cell and mediator biology to epidemiology attest to the continuing high standard of rheumatology research in these two countries.

To assist rheumatologists from the Asia/Pacific area to gain research experience APLAR has established a fellowship tenable in Australia, New Zealand, and Japan, and the Arthritis Foundation of Australia has established a study grant tenable in Australia. These grants are now highly sought after by rheumatologists throughout the area and it is hoped that this programme will expand in the years to come.

In closing, we should note that Australia continues to make a significant contribution towards the organisation of the International League Against Rheumatism with Professor K D Muirden (president) and Professor J P Edmonds (secretarygeneral). The area and population covered by the countries of the Pacific rim is enormous and delivery of health care services, rheumatological or otherwise, has to be approached somewhat differently than in Europe or North America. The events of recent months in the Middle East have, I am sure, emphasised the fragile world in which we live and the importance of friendship and cooperation as a counter to the destruction that man can wreak if negotiation cannot be continued. Let us hope that we, as rheumatologists, can use some of the world's diminishing resources for positive rather than negative ends. In preparing this report I would like to thank $\mathrm{Dr}$ John Darmawan, Indonesia; Professor Masashi Nobunaga, Japan; Dr
Clement Amante, the Phillipines; Dr Ed Li, Hong Kong; Dr P H Feng, Singapore; and Dr David Caughey, Auckland.

1 Muirden K. Community Oriented Programme for the Control of Rheumatic Diseases (COPCORD). APLAR Bulletin 1989; 7: 71-5.

2 Darmawan J. The quadrennial APLAR symposium on therapy of the rhevimatic diseases. 1990; 8: 29-30. 